\title{
28 Research Square \\ Gastric Metastasis From Ovarian Carcinoma Revealed by Digestive Hemorrhage: Case Report
}

\section{Hayat Erraichi1 ( $\nabla$ erraichierraichi@gmail.com )}

Oncohématologie Département, Center Hospitalier Louis Pasteur, 39 avenue de la Liberté, 68000 Colmar, France..

\section{Niaina Ezra RANDRIAMANOVONTSOA ${ }^{1}$}

Hopital Louis Pasteur

valère LITIQUE'

Hopital Louis Pasteur

Karima OUALLA ${ }^{2}$

Centre Hospitalier Universitaire Hassan II - Fes

\section{Zineb BENBRAHIM ${ }^{2}$}

Centre Hospitalier Universitaire Hassan II - Fes

\section{Nawfel MELLAS ${ }^{2}$}

Centre Hospitalier Universitaire Hassan II - Fes

Jean marc LIMACHER'

Hopital Louis Pasteur

\section{Case report}

Keywords: gastric metastases, digestive hemorrhage, ovarian cancer, biopsy

Posted Date: August 28th, 2020

DOI: https://doi.org/10.21203/rs.3.rs-46112/v1

License: (1) This work is licensed under a Creative Commons Attribution 4.0 International License.

Read Full License

Version of Record: A version of this preprint was published at American Journal of Biomedical Science \& Research on January 5th, 2021. See the published version at https://doi.org/10.34297/AJBSR.2021.11.001641. 


\section{Abstract}

\section{Background:}

Gastric metastases due to ovarian carcinoma are extremely rare and the patients' prognosis is poor. We report a case of gastric ovarian cancer metastases revealed by gastrosplenic perforation. The secondary gastric tumor appeared seven years after the diagnosis of primary cancer.

\section{Case presentation:}

The patient is a 71-year-old woman with a serous ovarian cancer hospitalized for asthenia with digestive hemorrhage. At esophagogastroduodenoscopy, a protruding mass was noted at the level of the gastric antrum. She underwent a hemostasis of an endoscopic hemostasis by argon plasma; with effective hemostasis. The final pathology revealed gastric metastases of serous ovarian adenocarcinoma. Weekly gemcitabine chemotherapy was adopted, but the disease progressed rapidly. The patient died 4 months later.

\section{Conclusion:}

We have reported a case of gastric metastasis of ovarian tumor origin revealed by digestive hemorrhage. This work reiterates that this secondary localization of this cancer is possible although extremely rare. Studies are still needed to elucidate much of this unclear situation.

\section{Background}

Gastric metastasis represents a rare situation. Several cancers can be at the origin but the primary ovarian is exceptionalHere we report a case of gastric metastasis from an ovarian tumor revealed by a digestive hemorrhage.

\section{Case Presentation}

A 71-year-old woman with a history of Raynaud's syndrome, pulmonary tuberculosis treated and declared cured, was followed up for a high-grade right ovarian cystadenocarcinoma with peritoneal carcinosis diagnosed in July 2013. The patient had received six cycles of neo-adjuvant chemotherapy carboplatin paclitaxel followed by oncology surgery and then three adjuvant cycles. She underwent a monobloc excision of the right annex + hysterectomy + left annexectomy + ommentectomy. The pathology of the operating room was in favor of a right ovarian cystadenocarcinoma followed by 3 cycles of carboplatin paclitaxel as adjuvant, in In July 2014, the CA 125 was three times normal, associated with a hyper metabolic mediastinal lymph node flow on the PET scanner. The administration of carboplatin gemcitabine bevacizumab made it possible to have a radiological remission and a normalization of CA 125. The patient refused to continue chemotherapy since January 2016. In October 2017 a massive lymph node and peritoneal resumption with clear rise in CA125 (six times normal) was controlled by 
cycles of carboplatin paclitaxel. In October 2019, the patient presented melena associated with asthenia, weight loss and anemia with a hemoglobin at $8 \mathrm{~g} / \mathrm{dl}$. The gastroscopy revealed a tumor formation under ulcerated mucosa, hemorrhagic, measuring $4 \mathrm{~cm}$ of long axis, heterogeneous, with bumpy contours at the expense mainly of the second layer at the level of the gastric antrum (Figure 1). The biopsy with anatomopathological study revealed an infiltration of the gastric wall by poorly differentiated carcinomatous proliferation whose immunohistochemistry phenotype in favor of an ovarian origin whose positivity of WT1 and p53 point towards a high rank serious carcinoma (Figure 2 ). The TAP scanner showed a gastric mass with lymph node metastasis and peritoneal carcinosis (Figure 3 ). The recurrence of melena with deglobulisation at $5.4 \mathrm{~g} / \mathrm{dl}$, required the achievement of an endoscopic hemostasis by plasma of Orgon and a transfusion of the pellet whose progress was favorable.Weekly gemcitabine chemotherapy was adopted, but the disease progressed rapidly. The patient died 4 months later.

\section{Discussion}

The authors . reports a case of gastric metastasis from an ovarian cystadenocarcinoma revealed by digestive hemorrhage after six years of diagnosis of the primary tumor. Secondary gastric localization is a rare situation [1]. Melanoma, breast, lung and esophageal cancers are the best known tumors responsible for secondary localization in the stomach [2,] . The primitive ovarian gastric metastasis is exceptional [3]. The literature reports only one case or a few series of cases. One study found 17 metastases of the stomach in 1010 patients with malignant tumors, a frequency of $1.7 \%$ [4]. Another series of autopsies uncovered 92 gastric metastases among 7,165 cases, with a rate of $1.28 \%$ [5]. In 2016, a systematic review of gastric metastases due to ovarian carcinoma was published [6], including a total of 18 case reports, ; to our knowledge our case is the 19th case of gastric metastasis with primary ovarian. Ovarian carcinoma usually metastasizes the peritoneal surfaces by exfoliating cells that implant throughout the peritoneum and the intraperitoneal dissemination route is the most common mode of dissemination, but the mechanism of gastric metastasis remains unclear, this may be due to the rich stomach blood supply [7] ,. The clinical manifestations are late and often nonspecific and include abdominal pain, vomiting, anorexia, digestive hemorrhage and anemia as in the case of our patient. The endoscopic aspect most often encountered is that of a single, nodular and ulcerated lesion of the type (valaco as ulcer) of variable gastric site. More rarely, metastases are of nodular appearance under single or multiple mucous membranes, or of linear appearance [2]. This appearance is very similar to a gastrointestinal stromal tumor (GIST). Kang et al. reported a case of primary ovarian carcinoma with gastric metastasis that looked like a GIST, diagnosed after antrectomy [8] Likewise, in our patient, we suspected that the gastric lesion was most probably a GIST taking into consideration the endoscopic aspect of the lesion. But on the basis of the patient's carcinological history and the histological result, we considered gastric metastasis of ovarian cancer.

\section{Conclusions}


We have reported a case of gastric metastasis of ovarian tumor origin revealed by digestive hemorrhage. This work reiterates that this secondary localization of this cancer is possible although extremely rare. Studies are still needed to elucidate much of this unclear situation.

\section{Declarations}

\section{Ethics approval and consent to participate:}

Not applicable

\section{Consent for publication:}

Consent from patient was obtained before publication of this case report.

\section{Availability of data and materials:}

The data are available from the corresponding author on reasonable request.

\section{Competing interests:}

The authors declare that they have no competing interests.

\section{Funding:}

None.

\section{Authors' contributions :}

HE wrote the article. RE, VL,: contributed in collecting clinical data,. KO, LA ,ZB and JML Critically review the article written. NM: final approval of the version to be published.

The work presented here was carried out in collaboration between all authors. All authors read and approved the final manuscript.

\section{Acknowledgements :}

None.

\section{Authors' details:}

- Oncohématologie Département, Center Hospitalier Louis Pasteur, 39 avenue de la Liberté, 68000 Colmar, France.. 
- Department of Medical Oncology, Hassan II University Hospital, Fes, Morocco

Hayat ERRACHI, , Karima Oualla, Zineb BENBRAHIM , Nawfal MELLAS, Jean-Marc LIMACHER .

\section{References}

1. Majerus B, Timmermans M. Gastric metastases of ovarian adenocarcinoma. A propos of a case. Acta ChirBelg1990; $90: 166-71$.

2. Menuck LS, Amberg JR. Metastatic disease involving the stomach. Am J Dig Dis $1975 ; 20$ : 903-13.

3. CaramellaE,brunetonJN,RouxP,AubanelD,Lecomte P. Metastases of the digestive tract. Report of 77 cases ans review of literature. Eur J Radiol1983; 3:31-8

4. Zhou JJ, Miao XY. Gastric metastasis from ovarian carcinoma: a case report and literature review. World J Gastroenterol 18: 6341- 6344, 2012.

5. Hwanqbo S, Kwon OK, Chung HY, Yu W. Improved survival of a patient with gastric and other multiple metastases from ovarian cancer by multimodal treatment: a case report. J Gastric Cancer 15: 218$221,2015$.

6. Angelo Zullo1, Giuseppina Balsamo2 , Roberto Lorenzetti1 , Adriana Romiti3 ,Vincenzo De Francesco4, Cesare Hassan1, Raffaele Manta:Gastric metastases from gynaecologic tumors: case reports and review of the literature.

7. Akce M, Bihlmeyer S, Catanzaro A. Multiple gastric métastases from ovarian carcinoma diagnosed by endoscopic ultra- sound with fine needle aspiration. Case Rep Gastrointest Med 2012;2012:610527.

8. Niederau C, Sobin LH. Secondary tumours of the stomach. In : Hamilton SR, Aaltoven LA ? EDS. Pathology and genetics of tumours of the Digestive System. Lyon : IARS Press $2000 ; 66$ -

\section{Figures}

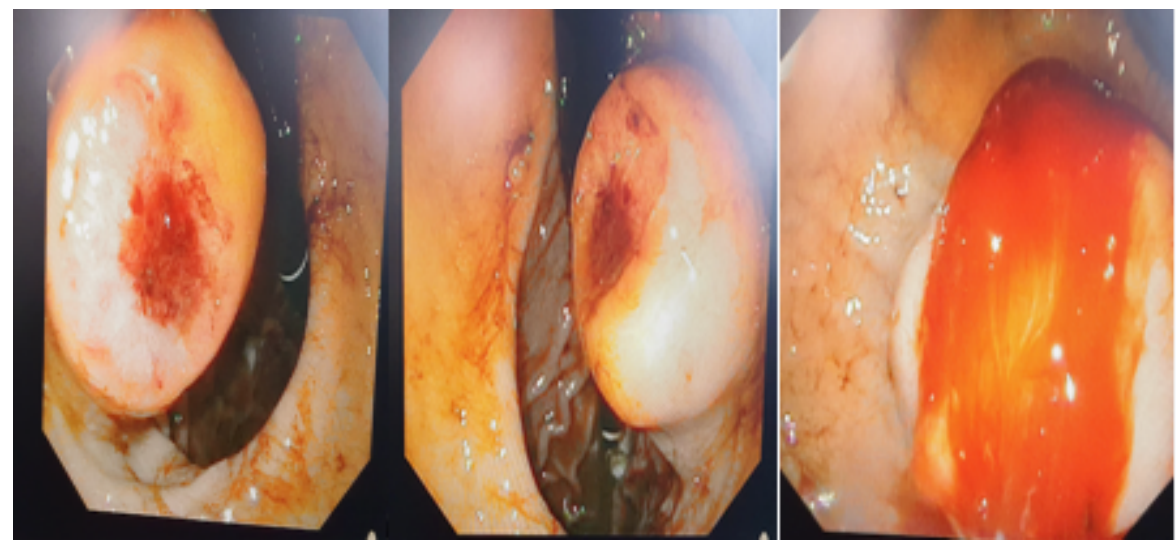

Figure 1 
Gastroscopy with endoscopy have highlighted the presence of a tumor formation under ulcerated mucosa measuring $4 \mathrm{~cm}$ of long axis, heterogeneous with bumpy contours mainly depending on the 2nd layer at the level of the gastric antrum.

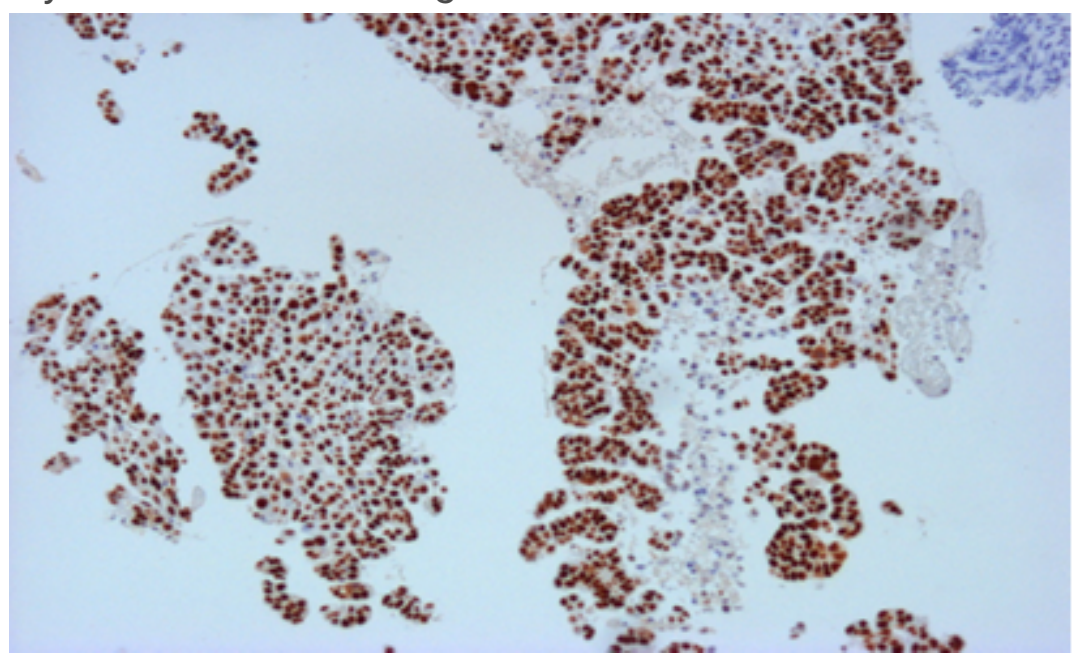

\section{Figure 2}

Histological examination of the gastric biopsy showing an infiltration of the gastric wall by poorly differentiated carcinomatous proliferation whose histochemical immune phenotype in favor of an ovarian origin whose WT1 positivity points towards a high grade serous carcinoma.

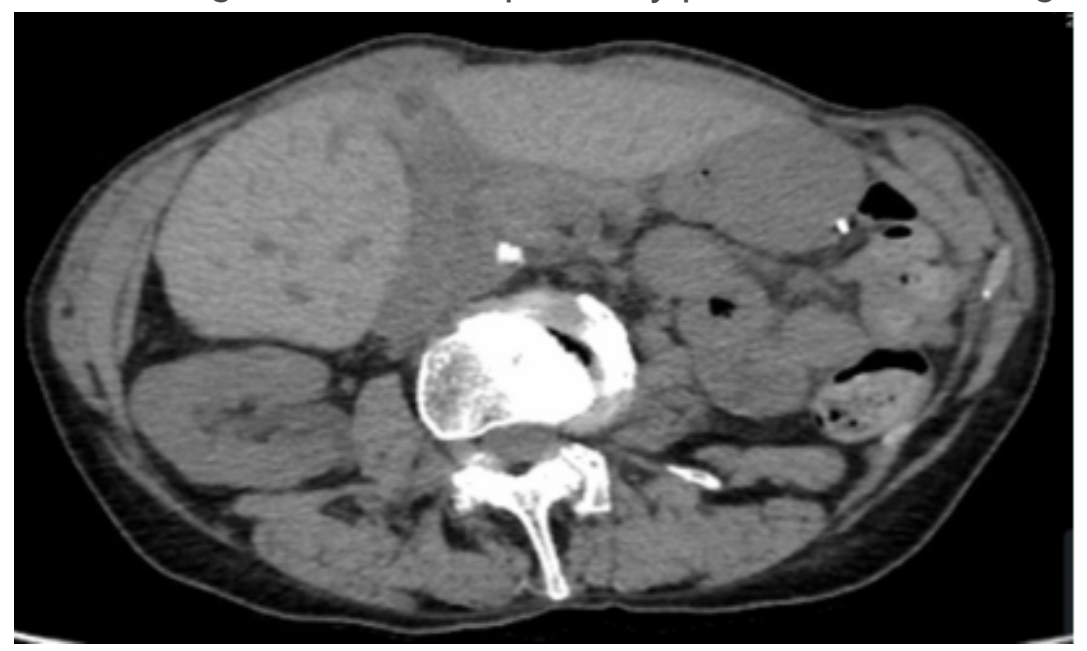

\section{Figure 3}

Abdominal computed tomography. showing a mass of the gastric antrum and the body 